\title{
Projeto Pedagógico de Curso e formação do psicólogo: uma proposta de análise
}

\author{
Pablo Sousa Seixas \\ Fellipe Coelho-Lima \\ Suzany Gadelha Silva \\ Oswaldo Hajime Yamamoto
}

\begin{abstract}
Resumo
O objetivo deste texto foi expor uma estratégia de análise de Projetos Pedagógicos dos Cursos (PPC) de Psicologia no Brasil. Compreende-se o PPC como um documento complexo e multideterminado, atravessado tanto pelas políticas educacionais quanto pelos anseios dos cursos, constituindo-se como um material importante para o estudo da formação do psicólogo. Contudo, a literatura não tem conseguido concatenar a aplicação de estratégias analíticas amplas a um grande número de casos. Construiu-se a presente estratégia a partir da legislação e literatura acerca da formação do psicólogo no país, bem como da leitura livre e categorizações de diferentes PPCs. Agruparam-se as informações desse documento em três blocos de discussões - fundamentos teóricos, filosóficos e pedagógicos; ênfases curriculares e disciplinas; práticas profissionais -, com as suas respectivas categorias analíticas. Considera-se que essa estratégia serve como inspiração para pesquisadores que se propõem a investigar a formação do psicólogo ou outros profissionais de nível superior.
\end{abstract}

Palavras-chave: Currículo, formação do psicólogo, educação superior.

\section{Pedagogic project of an undergraduate psychology course: an analysis proposal}

\begin{abstract}
In this text we propose an analysis strategy of Pedagogic Projects of Psychology Courses (PPC) in Brazil. The PPC, a complex and multideterminate document concerning both educational policies and course objectives, is an important tool in the study of psychology training. However, the literature has been unable to apply broad analytical strategies to a large number of cases. The present strategy was created based on legislation and literature regarding the training of psychologists in the country, as well as free reading and categorizations of different PPCs. Information in this document was grouped into three discussion blocks - theoretical, philosophical and pedagogical fundamentals; curricular and discipline issues; and professional practices -, with their respective analytical categories. This strategy is considered an inspiration to researchers who propose to investigate the education of psychologists or other university level professionals.
\end{abstract}

Keywords: Curriculum, psychologist education, higher education.

\section{Proyecto Pedagógico de Curso y formación del psicólogo: una propuesta de análisis}

\section{Resumen}

El objetivo de este trabajo fue presentar una estrategia de análisis de Proyectos Pedagógicos de Cursos (PPC) de Psicología en Brasil. Se entiende el PPC como un documento complejo e multideterminado, atravesado tanto por las políticas educacionales como por las expectativas de los cursos, constituyéndose un material importante para el estudio de la formación del psicólogo. Sin embargo, la literatura no ha conseguido concatenar la aplicación de estrategias analíticas amplias a un número expresivo de casos. La presente estrategia se construyó a partir de la legislación y literatura acerca de la formación del psicólogo en el país, así como de la lectura libre y de categorizaciones de diferentes PPCs. Las informaciones de este documento se agruparon en tres bloques de discusiones - fundamentos teóricos, filosóficos y pedagógicos; énfasis curriculares y disciplinas; prácticas profesionales - con sus respectivas categorías analíticas. Se considera que esta estrategia sirve como inspiración para investigadores que se proponen investigar la formación del psicólogo u otros profesionales de nivel superior.

Palabras clave: Curriculum, formación del psicólogo, educación superior. 


\section{Introdução}

O artigo tem por objetivo apresentar a construção e a descrição de uma estratégia de análise dos Projetos Pedagógicos de Curso (PPC) de Psicologia do Brasil. Essa proposta foi construída objetivando auxiliar nas investigações acerca do processo de formação em Psicologia no país. Acredita-se que a apresentação do processo de trabalho e a descrição da estratégia construída podem contribuir com outras pesquisas que focalizem o PPC como documento produtor de dados e com a compreensão do processo de formação em Psicologia de maneira geral. Além disso, o exame da literatura indica a escassez de estudos que levam em consideração o PPC como fonte de dados primária, restritos a um pequeno número de documentos (Abdalla e cols., 2009; Beck e cols., 2003; Freitas, Guedes, \& Silva, 2003; Lampert e cols., 2009).

No texto que se segue, serão apresentados os pressupostos de pesquisa, concepção de PPC e resgate bibliográfico no campo, seguidos de uma descrição da estratégia adotada em nosso estudo.

A presente estratégia foi construída tanto para dar suporte a pesquisas que intencionam estudar apenas um curso, como pesquisas que objetivem compreender aspectos do processo formativo em várias Instituições de Ensino Superior (IES) simultaneamente. O desafio metodológico foi de criar uma estratégia que, a partir dos PPCs, permitisse captar os aspectos mais amplos da formação do psicólogo, como os determinantes das políticas educacionais para ensino superior, por exemplo, sem perder de vista a análise interna do PPC, com suas particularidades teóricas filosóficas e caracterização técnico-instrumental. Trata-se de compreender o fenômeno em sua globalidade, ao mesmo tempo em que se respeitam os modos particulares com que este se apresenta na realidade concreta dos cursos. Assim, assume-se uma determinada concepção de PPC para a derivação da presente estratégia de análise.

\section{Projeto Pedagógico de Curso: concepção e determinantes}

O Projeto Pedagógico de Curso é um documento normativo dos cursos de graduação que apresenta características de projeto com informações acerca da concepção e da estrutura do curso e seus elementos reguladores internos. Nos PPCs estão presentes aspectos técnicos normativos, concepções de homem e de sociedade, além de um componente político fundamental, sendo elemento agregador de diversas instâncias da realidade, desde sua dimensão cotidiana dos cursos até diretrizes das políticas macroeconômicas.

Assim, o PPC deve propor o perfil de sujeito/profissional que se busca formar, no contexto da sociedade para qual se orienta essa formação. Representa, portanto, um entrelaçamento entre a organização de elementos da teoria e da prática, sendo definido pelo Fórum Brasileiro de Pró-
-Reitores de Graduação (ForGRAD, 1999) como tendo sua função prioritária orientar e conduzir intencionalmente o processo pedagógico, sendo organizado a partir de ponderações sobre as finalidades das atividades acadêmico-profissionais e, principalmente, sobre a concepção da educação e sua relação com a sociedade ${ }^{1}$.

Para fins de estruturação da estratégia de análise do PPC, adota-se a proposição organizativa apresentada por Veiga (2010), que contém três dimensões distintas: global, específica e particular. No primeiro grupo, localizam-se os determinantes extrainstitucionais, ligados, diretamente, a outras instâncias da sociedade, como a Constituição Federal e as regulamentações específicas da educação nacional - a Lei de Diretrizes e Bases da Educação (LDB) e o Plano Nacional de Educação (PNE). Ainda compõem esse grupo as demandas dos movimentos sociais e do mercado de trabalho. Na dimensão específica, residem as características de cada graduação, representadas no Plano Nacional de Graduação (PNG), e as especificidades de cada área, presentes nas Diretrizes Curriculares Nacionais dos Cursos (DCN). Por último, a dimensão particular refere-se ao desenvolvimento histórico de cada instituição e curso, os seus acúmulos de experiências pedagógicas, localização na dinâmica local/regional e o Plano de Desenvolvimento Institucional (PDI).

Diante desse panorama, é possível localizar o PPC, dentro do processo formativo, como um elemento que sintetiza as políticas mais amplas sobre a formação universitária e profissional, ao passo que se relaciona com a experiência particular da sala de aula. Ou seja, o PPC é um elemento que, ao mesmo tempo em que expressa diversos elementos oriundos das políticas educacionais para o ensino superior, também orienta a organização cotidiana da sala de aula.

Quanto à sua relação com a concretude do processo formativo, o PPC possui um forte rebatimento na sua operacionalização, traçando as linhas gerais para os procedimentos didáticos, pedagógicos e temáticos de um dado curso. Assim, no cotidiano das práticas de sala de aula, encontra-se o eco desse documento, juntamente com outros elementos particulares e idiossincráticos da cotidianidade (Veiga, 2010), como as experiências existentes na relação professor-aluno. Em outras palavras, cotejando com os documentos que determinam o PPC - como o PDI, as DCN e a LDB -, não se encontra neles a possibilidade de se compreender as realidades específicas de cada curso. Do mesmo modo, a análise das práticas cotidianas desenvolvidas em sala de aula levanta aspectos que são demasiadamente volúveis,

1 Sabe-se que as políticas educacionais brasileiras, mais amplamente a partir do estabelecimento da agenda neoliberal, têm sofrido sérias investidas de orientações do capital, nas quais as regulamentações nacionais são concatenadas aos interesses dos organismos internacionais como o Fundo Monetário Internacional (FMI), o Banco Mundial (BM) e a Organização Mundial do Comércio (OMC). Não sendo objeto deste estudo tais considerações mais profundas, é importante ressaltar a relevância dessas investidas no ordenamento e organização das relações sociais a partir deste grande setor que é a educação. Assim, para maiores aprofundamentos, aconselha-se o estudo: Chaui (2003), Catani, Oliveira e Dourado (2001) e Cunha (2003). 
pois se atrelam a componentes inconstantes da realidade do curso, como a interação entre um professor com a turma, ou de contingências particulares do momento, tais quais fatores ambientais.

Por seu turno, o PPC não deve ser um documento derivado unilateralmente dos condicionantes até agora postos, mas fruto dos debates e ações dos atores que compõem cada instituição e cada curso. Assim, o PPC pode assumir dois estatutos distintos de acordo com seu processo de construção. Em um caminho, ele configura-se como uma documentação burocrática, formulada por alguns consultores (internos ou externos ao curso), estabelecendo-se uma relação estritamente regulatória das práticas desenvolvidas pelos docentes. Em outra situação, o PPC apresenta-se como produto de um debate amplo desenvolvido entre docentes, técnicos, discentes e comunidade, promovendo a concatenação entre as expectativas desses atores e as restrições postas pelas legislações superiores (Veiga, 2010).

Por ser um fenômeno complexo, os PPCs necessitam de uma abordagem de análise que captasse aspectos das três dimensões assumidas nesse escrito. A proposição de uma estratégia própria de análise não poderia prescindir, no entanto, das possibilidades apresentadas na literatura, considerando a multiplicidade de questões constitutivas ao documento em questão.

\section{Estudos acerca dos Projetos Pedagógicos de Curso no Ensino Superior}

A utilização dos PPCs como fonte de dados em pesquisas sobre a formação no Ensino Superior não é novidade no Brasil. Esses estudos acontecem nas mais diversas áreas - Administração, Artes, Enfermagem, Filosofia, Fisioterapia, Matemática, Medicina, Psicologia, entre outros -, possuem estratégias de análise distintas e as informações derivadas desses assumem diferentes status de acordo com cada trabalho.

Constata-se essa realidade em uma rápida consulta à base de dados do Scielo e na Biblioteca Digital de Teses e Dissertações do Instituto Brasileiro de Informações em Ciência e Tecnologia (BDTD/IBICT). Lançando mão de descritores como "projeto pedagógico" e "proposta pedagógica", foi possível obter 28 trabalhos, entre dissertações, teses e artigos científicos, produzidos nas décadas de 2000 e 2010, que usaram o PPC como fonte de informações para suas pesquisas. A exposição que seguirá, longe de pretender a realização de um estado da arte sobre estudos que utilizam o PPC como material de pesquisa, pretende esboçar um quadro geral de alguns casos em que se utiliza esse material. Merecem destaque algumas conformações inerentes a esse material.

Primeiramente, é possível distinguir quatro formas de se abordar o PPC como objeto analítico: pelo tema específi$\mathrm{co}$, pelas dimensões internas do PPC, pelo alinhamento com outros documentos e pelas determinações externas do PPC. Identificou-se também um quinto grupo que, por não adotar o PPC como fonte de dados de pesquisa, distancia-se metodologicamente dos demais trabalhos. Esse conjunto possui um grande volume de materiais e narra o processo de elaboração dos projetos pedagógicos dos cursos ou apresenta projetos pedagógicos fundamentados em estudos teóricos.

Ainda há dois pontos principais que caracterizam esses estudos: a baixa quantidade de casos analisados e a associação da análise de PPC com outras fontes de dados. Quanto ao primeiro quesito, a maioria das pesquisas optou pela focalização em apenas um curso (Beck e cols., 2003; Freitas e cols., 2003), havendo alguns poucos estudos que utilizavam, no máximo, oito cursos como casos para análise (Abdalla e cols., 2009; Lampert e cols., 2009). Já as outras fontes de dados de pesquisas circulam em torno de entrevistas ou grupo de discussões com coordenadores, docentes ou discentes, análise de documentos regulatórios (como as DCN dos cursos e o PDI) e de planos de ensino das disciplinas.

Esse cenário esboçado nos parágrafos anteriores revela um conjunto de pesquisas que buscam serem informadas por meio do PPC sobre aspectos específicos da formação. São estudos que priorizam a compreensão de uma realidade singular e, para tanto, partem de referenciais analíticos qualitativos, havendo poucos autores que adotam o PPC como material único de análise.

Como já discutido em seções anteriores, o Projeto Pedagógico de um curso encerra em si uma miríade de informações, com significados distintos, que revelam facetas diversas do processo formativo. Contudo, nos trabalhos consultados, o que se verificou foi mais a busca por uma triangulação das fontes de dados do que necessariamente o esgotamento desse material documental.

Nessa direção, estudos que almejam a compreensão mais ampla do fenômeno formativo em diversas realidades e que contemplam uma caracterização ampla dessa formação acabam por demandar uma estratégica analítica diferenciada. Corroboram essa afirmação os estudos de Abdalla e cols. (2009) e Lampert e cols. (2009) que, ao preterirem uma análise ampla do cenário formativo em Medicina, empreenderam a construção de um instrumento analítico próprio.

No tocante à apropriação que os estudos sobre a formação em Psicologia fazem dos PPCs, fica clara a escassez de trabalhos que priorizem esse material como foco de análise. Diferentemente de outros campos - como a Pedagogia, Enfermagem e Medicina -, na Psicologia, os estudos sobre a formação não se valem do PPC como fonte primária de dados de pesquisa. Além disso, soma-se a dificuldade da literatura, proveniente de outros campos, em apresentar estratégias de análise do PPC que concatenem a complexidade desse documento com o estudo de um grande número de cursos.

Embora se defenda a posição de que cada estratégia responda a um problema específico, não se pode negar objetivamente que, com base no exame bibliográfico levantado, faltam estratégias e técnicas de análise do PPC que considerem seu conteúdo filosófico epistemológico e estrutura curricular de forma a não só compreender o curso 
em questão, mas permitir compará-lo com outras realidades num recorte transversal nacional.

Desse modo, para a compreensão da formação do psicólogo em contextos distintos, torna-se patente a necessidade de construção de uma estratégia analítica que se oriente tanto pela especificidade desse fenômeno, como leve em consideração a riqueza e complexidade dos PPCs como fonte de informação científica.

\section{Elaboração e funcionamento da estratégia de análise dos PPCs em Psicologia}

Nesta seção será descrito o processo de construção da estratégia de análise e quais os elementos que a compõem. Esse modelo de análise toma os pressupostos até aqui elencados, considerando-se como um pano de fundo para as possíveis investigações sobre a formação do psicólogo no Brasil.

\section{Concepção e elaboração da estratégia}

Como primeiro passo na tentativa de construção do instrumento, foi necessária uma primeira imersão na realidade dos cursos de formação de psicólogo. Foram analisados os documentos que legislam a respeito do Ensino Superior nos próprios PPCs e a literatura que versava a respeito da formação universitária e da formação do psicólogo.

Nesse processo, constatou-se, na leitura da LDB (Lei $n^{\circ}$ 9.394,1996), a prescrição da existência de projetos pedagógicos de cursos, mas sem a definição dos elementos que devem constar nos PPCs. Diante dessa situação, partiu-se para uma leitura preliminar de alguns PPCs de Psicologia do país com a intenção de levantar dimensões que estavam contempladas na maioria dos documentos.

Realizando a leitura de dez projetos pedagógicos de cursos com características diversas (quantidade de vagas, tempo de existência, localização regional, natureza jurídica e organização acadêmica), foi possível identificar três blocos que estruturavam, de maneira geral, esses documentos (Figura 1)

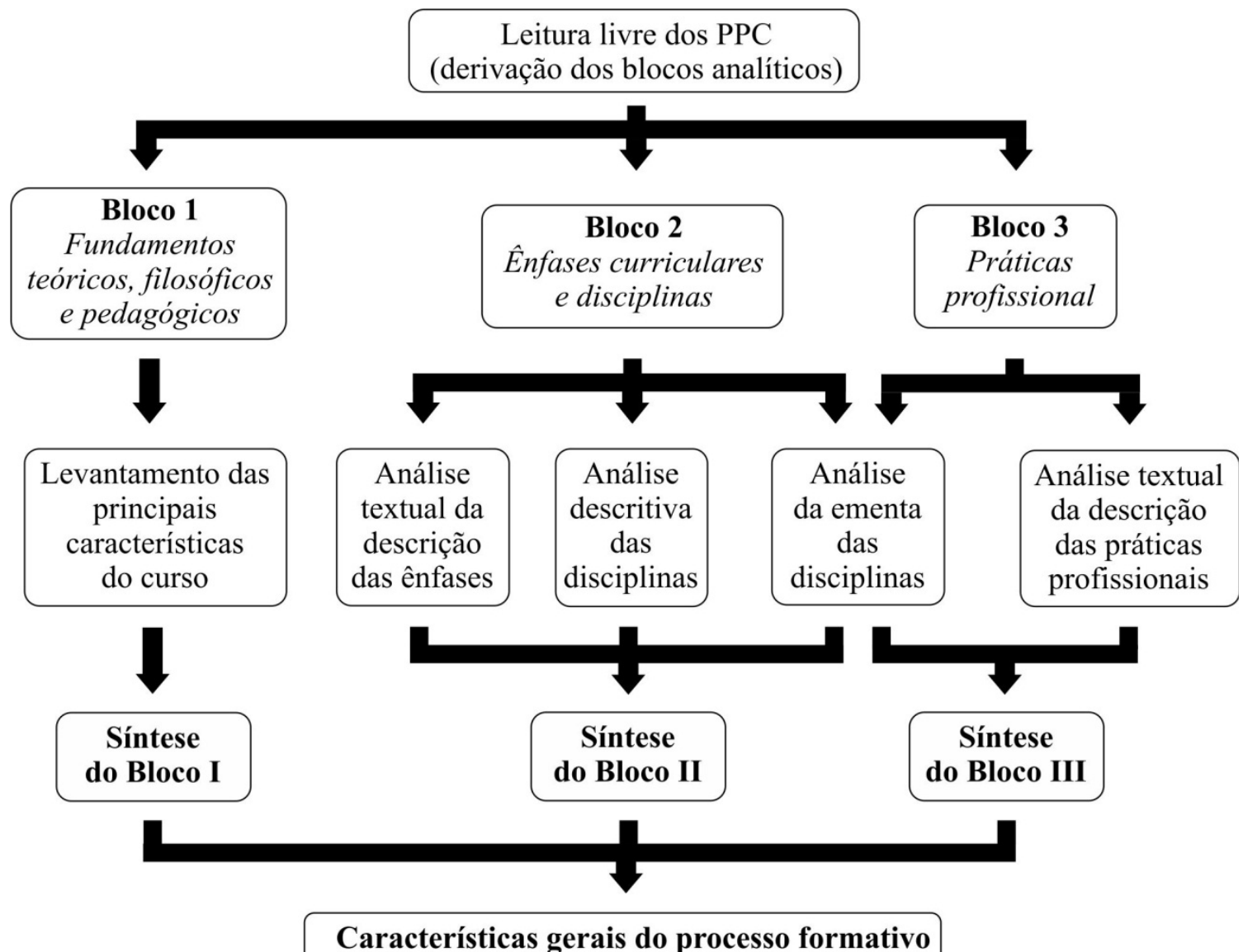

Figura 1. Fluxugrama simplificado da estratégia de análise. 


\section{Bloco I - Fundamentos teóricos, filosóficos e pedagógicos}

O primeiro bloco refere-se aos fundamentos teóricos, filosóficos e pedagógicos que são apresentados nos PPCs. Além desses elementos, também se encontram a descrição do funcionamento geral do curso, alguns dados institucionais (quantidade de vagas, turno de funcionamento, quantidade de docentes etc.) e o histórico do curso. Mesmo havendo uma diversificação das informações tratadas nessa seção dos documentos, priorizando os temas que estão presentes na maioria dos PPCs, levantaram-se como tópicos para análise: o perfil do egresso, o processo formativo, as justificativas para a existência do curso e para a mudança curricular e o histórico do curso.

O perfil do egresso refere-se ao profissional em Psicologia que se pretende formar, que características ele deve conjugar e quais competências e habilidades são esperadas, desse psicólogo, ao término dos anos do curso. O processo formativo, por sua vez, trata das estratégias de ensino previstas para que o perfil do egresso seja alcançado, como contato com profissionais formados, experiências de extensão e pesquisa, participação direta na comunidade, entre outras. Já a justificativa desdobra-se em duas subcategorias: da existência do curso e da reforma curricular. Ambas pretendem levantar as demandas e necessidades que as graduações em Psicologia tentam atender, sejam elas puramente legais ou expressão de uma conformação regional específica. Por fim, a categoria histórico do curso intenta levantar alguns aspectos históricos que compõem a conformação atual da formação do psicólogo em um dado curso.

Em suma, tais categorias analíticas tentam responder qual a conformação do curso e seus determinantes intrínsecos para o planejamento do currículo e das demais atividades pedagógicas.

\section{Bloco II - Ênfases curriculares e disciplinas}

Esse se constitui em um dos maiores blocos de análise, por agrupar duas dimensões que compõem os PPCs: a descrição das ênfases curriculares e a matriz curricular.

\section{Ênfases curriculares}

Como previsto pela Resolução 005/11 (2011) do Conselho Nacional de Educação, que legisla atualmente sobre as Diretrizes Curriculares Nacionais para o curso de Psicologia - em substituição à Resolução CNE/CFE n 08 de 2004, a primeira a instituir essa formatação aos cursos -, é necessária a divisão do curso em dois momentos: núcleo comum e ênfases curriculares. O primeiro refere-se a "uma base homogênea para a formação no País (sic) e uma capacitação básica para lidar com os conteúdos da Psicologia, enquanto campo de conhecimento e de atuação" (Resolução 005/11, 2011, p. 3). Já as ênfases curriculares constituem-se no momento do curso em que o discente tem a oportunidade de aprofundar o conhecimento em alguns domínios da Psicologia, mas sem se constituir enquanto especialização. A escolha dos cursos pelas ênfases respeita as demandas da localidade na qual ele está inserido, a conformação do corpo docente, as vocações institucionais e as competências básicas pensadas para o psicólogo. Assim, a definição das ênfases constitui-se em um dos caminhos pelo qual o curso operacionaliza os seus pressupostos presente no Bloco I.

A análise das ênfases curriculares, por seu turno, é assentada sob o texto do PPC que discorre a respeito destas, centrando-se nas seguintes categorias analíticas: o foco da ênfase, o perfil do egresso da ênfase, a justificativa para criação da ênfase, o processo formativo dentro da ênfase e seu funcionamento interno. A primeira categoria refere-se ao ponto central tratado na ênfase: se em alguma área específica da Psicologia, em um tema, um contexto de atuação, um terminado período do ciclo vital, entre outros. Assim como as categorias do Bloco I, o perfil do egresso da ênfase faz alusão a que especificidades deve possuir o psicólogo que optou por passar por determinada ênfase (quais os contextos são mais recomendados para sua atuação, que competências específicas são desenvolvidas etc.). O processo formativo da ênfase trata das atividades pedagógicas previstas para alcançar o perfil do egresso da ênfase esperado - relação semelhante à existente no Bloco I. A justificativa da ênfase retrata que determinantes foram levados em consideração para a divisão do curso nas ênfases curriculares construídas. Por fim, o funcionamento interno da ênfase revela como uma ênfase curricular específica articula-se com os outros momentos do curso e como são conduzidas as atividades pedagógicas no seu interior.

\section{Matriz Curricular}

Já a análise das disciplinas segue uma lógica distinta, considerando a natureza das informações que elas oferecem. As disciplinas que serão analisadas são as obrigatórias. As disciplinas optativas, além de não constarem nos PPCs, podem sofrer modificações sem avisos prévios, o que tornaria de pouca utilidade para uma análise nacional. Para a construção do plano de análise da matriz curricular, consideraram-se duas questões basilares. Primeiramente, é necessário compreender a matriz curricular como um todo complexamente organizado de disciplinas, que possui uma fluidez e é determinada por elementos intrínsecos ao curso e extrínsecos à instituição. Em segundo lugar, é imperativo considerar que as disciplinas possuem status diversos dentro do curso. Em outras palavras, tendo em vista a sua localização na matriz curricular, em termos verticais (relação com disciplinas de períodos diferentes), horizontais (interação com as disciplinas do mesmo período) e o tipo de conteúdo tratado (técnico, teórico, epistemológico, de outros campos do conhecimento etc.), cada disciplina acaba por assumir uma singularidade de acordo com o curso que pertence. Desse modo, surge o desafio de estabelecer parâmetros de 
análise que, por um lado, não pervertam essa conformação da realidade, mas que, ao mesmo tempo, permitam captar, por meio das disciplinas, elementos que versem a respeito do processo formativo do psicólogo.

Para fazer face a essa tarefa, foram considerados dois conjuntos de informações. Um é composto por dados eminentemente descritivos, como a carga horária, o período ao qual é vinculada e o momento do curso a que pertence (núcleo comum ou ênfase curricular), e o outro diz respeito ao conteúdo presente nas ementas.

Por outro lado, embora as disciplinas apresentem idiossincrasias, elas respondem legalmente às DCN para o curso de Psicologia (Resolução $n^{\circ}$ 005, 2011). Esse documento determina, no Artigo $5^{\circ}$, que as matrizes curriculares contemplem os conhecimentos, competências e habilidades em torno de seis eixos estruturantes, independentemente do formato que cada disciplina queira adotar. Dito isso, a leitura prévia de diversos PPCs fez com que se percebesse uma maior semelhança entre os conteúdos expressos nas ementas das disciplinas que respondem ao mesmo eixo estruturante do que comparadas com as de eixos distintos. Percebeu-se também que essa organização do material oferece subsídios para responder às principais questões da formação em Psicologia postas pela literatura. Procedeu-se então a uma interpretação da definição de cada um dos seis eixos a fim de operacionalizá-los em categorias analíticas para a pesquisa. Além disso, a revisão bibliográfica empreendida (Bastos \& Aschar, 1994; Bastos, Gondim, Souza, \& Souza, 2011; Mello, 1975; Yamamoto, Da Rocha Falcão, \& Seixas, 2011) permitiu transformar os dilemas mais comuns na formação de psicólogo em subcategorias dentro de cada eixo ${ }^{2}$. Cabe ressaltar que algumas características do conteúdo das disciplinas foram consideradas transversais aos eixos e suas categorizações não se restringem às opções impostas, girando em torno de três discussões: ética, área da Psicologia e conhecimentos sobre a realidade brasileira.

Essa atividade de interpretação do texto da Resolução 005/11 (2011) e de criação das subcategorias analíticas pode ser conferida no Quadro 1, que expõe o texto original da legislação supracitada e a definição elaborada para efeitos da pesquisa.

Como é possível visualizar no Quadro 1, as reinterpretações tiveram por objetivo clarificar pontos nodais das definições existentes na legislação, tentando ora oferecer saídas operacionais que permitissem a identificação dos eixos nas matrizes curriculares, ora restringir a definição, a fim de tornar a categoria dos eixos estruturantes excludentes entre si. Já as subcategorias analíticas elencadas tentaram,

2 Seguindo a revisão bibliográfica operada por Lisboa e Babosa (2009), foi possível levantar alguns dos dilemas mais comuns no campo da formação do psicólogo, como: "formação técnica versus crítico-reflexiva, científica versus profissional, generalista versus especialista, predominantemente clínica versus pluralista, unidisciplinar versus multi/interdisciplinar, histórica versus contemporânea, elitista versus socialmente comprometida e voltada para indivíduos versus voltada para a coletividade" (Lisboa \& Barbosa, 2009, p. 724). dentro do escopo pertinente a cada um dos eixos estruturantes, responder aos questionamentos presentes na literatura.

Tomando a especificidade da construção textual das ementas, a resposta sobre a pertença de uma disciplina a um eixo é dada pelos diversos trechos que compõem esse texto. Os fragmentos das ementas, por sua vez, podem referir-se a mais de um eixo estruturante, o que permite uma disciplina responder às demandas de eixos variados. Essa configuração reflete um movimento que ocorre comumente em alguns cursos de congregarem-se, em uma única disciplina, conteúdos de status distintos, sendo inviável pensar-se em um conteúdo central.

A análise das disciplinas, assim posta, segue dois caminhos: um de classificação dos trechos das ementas de acordo com os eixos estruturantes e outro de preenchimento das subcategorias analíticas. No primeiro momento, realiza-se uma organização dos dados textuais, classificando os trechos das ementas de acordo com a definição de cada eixo, sendo possível uma ementa responder aos diversos eixos ao mesmo tempo. Já no segundo momento, com os fragmentos organizados, respondem-se às subcategorias correspondentes a cada eixo. Exemplificando, uma determinada ementa que possui trechos pertencentes ao eixo $A$ e $B$ apenas terá preenchido as subcategorias correspondentes a esses eixos, sendo os demais não preenchidos.

\section{Bloco III - Práticas profissionais}

Assim como o Bloco II, as práticas profissionais referem-se ao modo como o curso operacionaliza os seus pressupostos teóricos, filosóficos e pedagógicos, distinguindo-se do bloco precedente por focalizar atividades eminentemente práticas que buscam concatenar o exercício profissional com os conteúdos teóricos do curso. As especificações quanto a essa temática encontram-se tanto nas ementas das disciplinas como em trechos do PPC. De maneira geral, o conteúdo tratado refere-se aos estágios - tanto básicos, como profissionalizantes -, mas não se restringe a eles, todo texto que prescreva expressamente uma atividade prática está incluído nesse bloco. Esses textos permitem ilações a respeito de quatro temas distintos sobre a prática profissional: os locais em que são realizadas as práticas, o funcionamento dos estágios, a relação entre os tipos de estágios e as atividades previstas.

A categoria de locais de prática profissional refere-se às determinações prévias quanto aos contextos em que o discente pode/deve inserir-se a fim de se preparar profissionalmente. O funcionamento dos estágios pretende desvelar o modo como eles são operacionalizados, trazendo uma narrativa a respeito da articulação das atividades internas a cada estágio. A relação entre os estágios apresenta o modo como o curso relaciona os distintos estágios obrigatórios existentes. Os objetivos dos estágios expressam o que cada estágio pretende responder, de acordo com a documentação dos cursos. Por fim, a categoria de atividades previstas 
Quadro 1. Descrição dos eixos estruturantes e das subcategorias analíticas

\begin{tabular}{|c|c|c|}
\hline $\begin{array}{l}\text { Nome do eixo } \\
\text { estruturante }\end{array}$ & Texto original do artigo $5^{\circ}$ da Resolução $005 / 11$ & Definição operacional utilizada na pesquisa \\
\hline $\begin{array}{l}\text { Eixo A } \\
\text { Fundamentos } \\
\text { epistemológicos e } \\
\text { históricos }\end{array}$ & $\begin{array}{l}\text { Fundamentos epistemológicos e históricos que } \\
\text { permitam ao formando o conhecimento das bases } \\
\text { epistemológicas presentes na construção do saber } \\
\text { psicológico, desenvolvendo a capacidade para } \\
\text { avaliar criticamente as linhas de pensamento em } \\
\text { Psicologia. }\end{array}$ & $\begin{array}{l}\text { Incluem as discussões que resgatam componentes } \\
\text { históricos e/ou epistemológicos do conteúdo } \\
\text { tratado na disciplina, seja da Psicologia como } \\
\text { ciência ou profissão, de um campo da Psicologia, } \\
\text { um tema, objeto, procedimento, técnica ou } \\
\text { qualquer outro tipo de material. }\end{array}$ \\
\hline $\begin{array}{l}\text { Eixo B } \\
\text { Fundamentos } \\
\text { teórico- } \\
\text { metodológicos }\end{array}$ & $\begin{array}{l}\text { Fundamentos teórico-metodológicos que } \\
\text { garantam a apropriação crítica do conhecimento } \\
\text { disponível, assegurando uma visão abrangente } \\
\text { dos diferentes métodos e estratégias de produção } \\
\text { do conhecimento científico em Psicologia. }\end{array}$ & $\begin{array}{l}\text { Participam os conteúdos que tratam de } \\
\text { pressupostos teóricos e/ou metodológicos mais } \\
\text { amplos. Costumeiramente, são pressupostos } \\
\text { aplicáveis a temas, objetos, técnicas e estratégias } \\
\text { de intervenção específicas. }\end{array}$ \\
\hline $\begin{array}{l}\text { Eixo C } \\
\text { Procedimentos } \\
\text { para a investigação } \\
\text { científica e a } \\
\text { prática profissional }\end{array}$ & $\begin{array}{l}\text { Procedimentos para a investigação científica e } \\
\text { a prática profissional, de forma a garantir tanto } \\
\text { o domínio de instrumentos e estratégias de } \\
\text { avaliação e de intervenção quanto a competência } \\
\text { para selecioná-los, avaliá-los e adequá-los a } \\
\text { problemas e contextos específicos de investigação } \\
\text { e ação profissional. }\end{array}$ & $\begin{array}{l}\text { É composto pela apresentação de técnicas, } \\
\text { estratégias, procedimentosou qualquer arcabouço } \\
\text { instrumental para o processo de pesquisa e } \\
\text { intervenção em Psicologia. }\end{array}$ \\
\hline $\begin{array}{l}\text { Eixo D } \\
\text { Fenômenos } \\
\text { e processos } \\
\text { psicológicos }\end{array}$ & $\begin{array}{l}\text { Fenômenos e processos psicológicos que } \\
\text { constituem classicamente objeto de investigação } \\
\text { e atuação no domínio da Psicologia, de forma } \\
\text { a propiciar amplo conhecimento de suas } \\
\text { características, questões conceituais e modelos } \\
\text { explicativos construídos no campo, assim como } \\
\text { seu desenvolvimento recente. }\end{array}$ & $\begin{array}{l}\text { Abarca as discussões a respeito de objetos } \\
\text { específicos com que a Psicologia lida. }\end{array}$ \\
\hline $\begin{array}{l}\text { Eixo E } \\
\text { Interfaces com } \\
\text { campos afins do } \\
\text { conhecimento }\end{array}$ & $\begin{array}{l}\text { Interfaces com campos afins do conhecimento } \\
\text { para demarcar a natureza e a especificidade } \\
\text { do fenômeno psicológico e percebê-lo em sua } \\
\text { interação com fenômenos biológicos, humanos e } \\
\text { sociais, assegurando uma compreensão integral } \\
\text { e contextualizada dos fenômenos e processos } \\
\text { psicológicos. }\end{array}$ & $\begin{array}{l}\text { São os conteúdos que são eminentemente de } \\
\text { outros campos do saber e que historicamente não } \\
\text { foram apropriados pela Psicologia. }\end{array}$ \\
\hline $\begin{array}{l}\text { Eixo F } \\
\text { Práticas } \\
\text { profissionais }\end{array}$ & $\begin{array}{l}\text { Práticas profissionais voltadas para assegurar } \\
\text { um núcleo básico de competências que permitam } \\
\text { a atuação profissional e a inserção do graduado } \\
\text { em diferentes contextos institucionais e sociais, de } \\
\text { forma articulada com profissionais de áreas afins. }\end{array}$ & $\begin{array}{l}\text { Estão incluídas as disciplinas que preveem, } \\
\text { explicitamente, alguma atividade prática ou } \\
\text { que se colocam como espaços para integrar } \\
\text { os conhecimentos debatidos em um período } \\
\text { específico - sem apresentar conteúdos novos, } \\
\text { necessariamente. }\end{array}$ \\
\hline
\end{tabular}

elenca as práticas profissionais específicas que são prescritas para serem realizadas durante o curso.

Também estão integradas nesse bloco as informações acerca das disciplinas que preveem atividades práticas. Assim, os dois conjuntos de dados que emergem desse objeto são contemplados: os elementos descritivos contidos em diferentes partes do PPC e os presentes nas ementas (como consta no Quadro 1).

\section{Concatenação das informações}

Como se pode inferir, a análise específica do PPC, norteada pelos três blocos de discussões expostos, impele o levantamento de dados e considerações diversas. Essa massa de dados informa acerca de diversas características do fenômeno formação do psicólogo. A fim de compilar os blocos e suas respectivas categorias analíticas, a Figura 2 apresenta resumidamente esses elementos. 

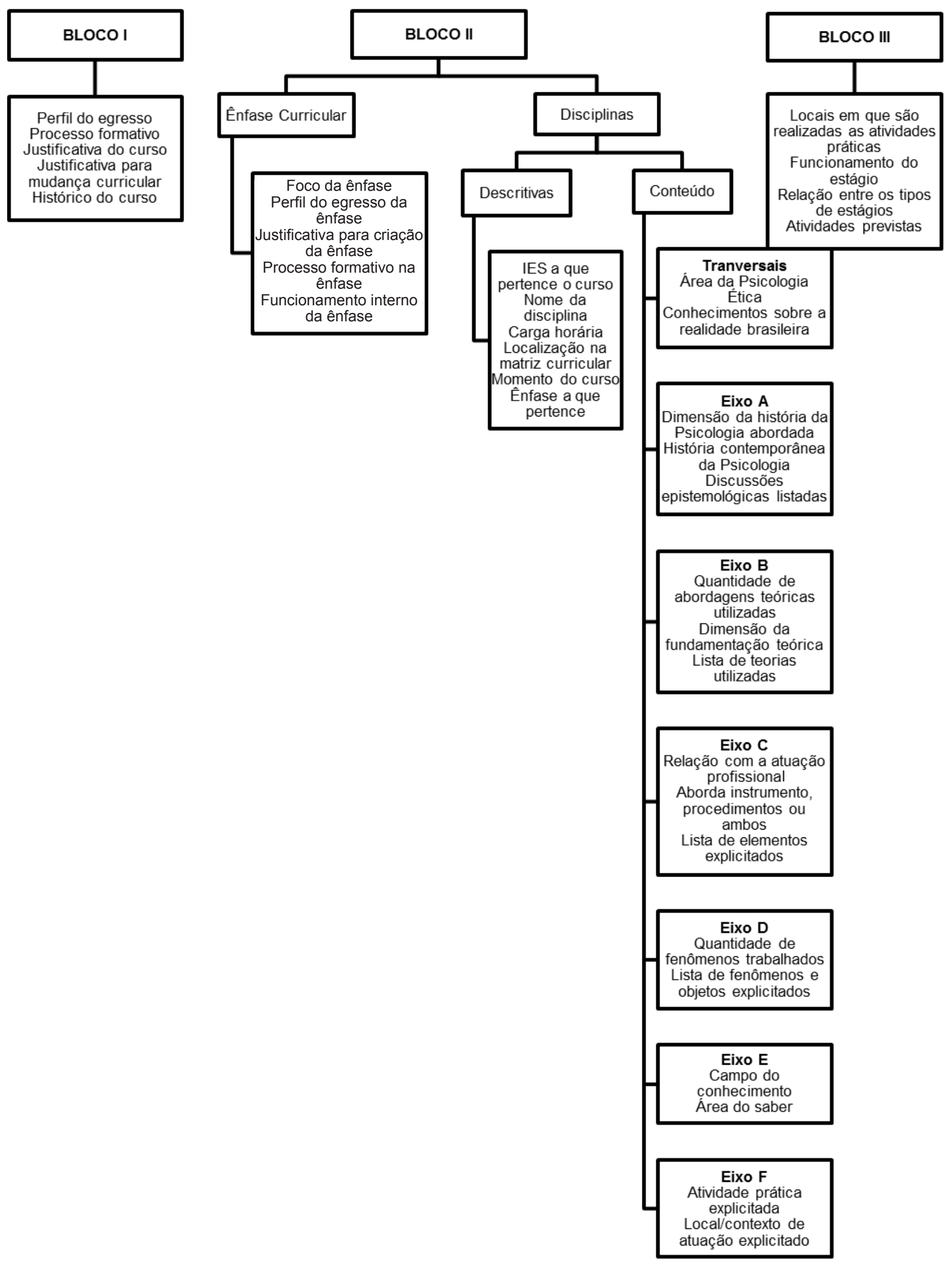

Figura 2. Blocos de Discussão e categorias analíticas levantadas 
Dessa forma, o último procedimento de análise é compilar em um curso as sínteses discursivas de cada uma das três dimensões trabalhadas (fundamentos teórico-filosóficos; ênfases curriculares e disciplinas; prática profissional). Esses textos são a narrativa da apreensão do pesquisador sobre os dados e informações presente em cada bloco analítico, servindo como um condensador das principais características que podem ser levantadas a partir das categorias utilizadas. Por sua vez, essas três sínteses originam uma análise única da realidade de cada curso específico.

O processo analítico aqui descrito permite compor um cenário amplo das principais características de cada curso, o qual possibilita a visualização das diversas realidades dos cursos de psicólogo. Por fim, a visualização desse conjunto textual oferta o potencial de apreensão de elementos importantes presentes na formação do psicólogo no Brasil.

\section{Considerações Finais}

É sabido que um dos grandes desafios dessa proposta é articular fenômeno formativo processual sem perder de vista as particularidades de cada curso analisado. Mesmo com essa limitação, acredita-se que essa proposta pode obter êxito ao considerar as orientações das DCN como pontos de análise, permitindo dar conta dos diferentes níveis presentes no PPC, da dimensão transversal das políticas para educação superior às realidades locais.

Sem a intenção de prescrever procedimentos para analisar os PPCs de Psicologia, espera-se que a apresentação dessa estratégia e de seu embasamento teórico sirva de inspiração para outros pesquisadores estudarem aspectos do processo formativo a partir desse complexo documento. Sabe-se também que as escolhas dos eixos estruturantes contidos nas DCN como forma de organização da informação podem restringir o uso da estratégia apenas para os cursos de Psicologia. No entanto, a forma de construção da presente estratégia, em articulação com as respectivas legislações de cada área do conhecimento, poderia servir para acrescentar outra reflexão nas maneiras de análise possíveis para o campo, que, como visto na revisão bibliográfica, ainda carece de estudos que se proponham a abordar uma grande quantidade de documentos sem o apoio de fontes de dados adicionais.

A presente proposta insere-se no escopo de outras estratégias possíveis de análise do PPC. Acredita-se que, com a adoção tanto de bases teóricas e metodológicas diferentes, como de outros objetivos - além da investigação sobre o processo formativo global do psicólogo -, poderia se construir estratégias de análises distintas. Espera-se, por fim, que a apresentação dessa estratégia auxilie no caminho de estudos que visem elucidar a discussão sobre a formação em Psicologia, tão em voga e relevante nos dias de hoje.

\section{Referências}

Abdalla, I. G., Stella, R. C. R., Perim, G. L., Aguilar-da-Silva, R. H, Lampert, J. B., \& Costa, N. M. S. C. (2009). Projeto pedagógico e as mudanças na educação médica. Revista Brasileira de Educação Médica, 33(1,Supl. 1), 44-52.

Bastos, A. V. B., \& Ashcar, R. (1994). Dinâmica profissional e formação do psicólogo: Uma perspectiva de integração. Em Conselho Federal de Psicologia (Org.), Psicólogo Brasileiro: Práticas emergentes e desafios para a formação (pp. 245-271). São Paulo: Casa do Psicólogo.

Bastos, A. V. B., Gondim, S. M. G, Souza, J. A. J., \& \& Souza, M. P. R. (2011). Formação básica e profissional do psicólogo: uma análise do desempenho das IES no ENADE-2006. Avaliação Psicológica, 10(3), 313-347.

Beck, C. L. C., Budó, M. L. D., Terra, M. G., Camponagara, S., Padoin, S. M. M., \& Blois, J. M. (2003). Participação na construção de um projeto político pedagógico na Enfermagem. Revista Brasileira de Enfermagem, 56(4), 405-408.

Catani, A. M., Oliveira, J. F., \& Dourado, L. F. (2001). Política educacional, mudanças no mundo do trabalho e reforma curricular nos cursos de graduação no Brasil. Revista Educação \& Sociedade, 75, 67-83.

Chaui, M. (2003). A universidade pública sob nova perspectiva. Revista Brasileira de Educação, 24, 5-15.

Cunha, L. A. (2003). O ensino superior no octênio FHC. Revista Educação \& Sociedade 24, 3-61.

ForGrad. (1999). Fórum de Pró-Reitores de Graduação das Universidades Brasileiras. Do Pessimismo da Razão ao Otimismo da Vontade: referências para a construção de Projetos Pedagógicos nas IES Brasileiras. Recuperado: 10 Mai. 2013. Disponivel: http://forgrad.com.br/publicacoes.php.

Freitas, M. C., Guedes, M. V. C., \& Silva, L. F. (2003). Curso de Enfermagem da Universidade Estadual do Ceará - a história e o projeto político-pedagógico atual. Revista Brasileira de Enfermagem, 56(4), 385-387.

Lampert, J. B., Perim, G. L., Aguilar-da-Silva, R. H., Stella, R. C. R., Abdala, I. G., \& Costa, N. M. S. C. (2009). Mundo do trabalho no contexto da formação médica. Revista Brasileira de Educação Médica, 33(1, Supl.1), 35-43.

Lei $N^{\circ} 9.394$ de 20 de dezembro de 1996. (1996). Estabelece as Diretrizes e Bases da Educação Nacional. Brasília: DF. Recuperado: 25 Jul. 2012. Disponível: http://portal.mec.gov.br/ seed/arquivos/pdf/tvescola/leis/lein9394.pdf.

Lisboa, F. S., \& Barbosa, A. J. G. (2009). Formação em Psicologia no Brasil: Um Perfil dos Cursos de Graduação. Psicologia Ciência e Profissão, 29(4), 718-737. 
Mello, S. L. (1975). Psicologia e profissão em São Paulo. São Paulo: Ática.

Resolução do Conselho Nacional de Educação/Câmara de Educação Superiorn ${ }^{\circ}$ 005. (2011). Institui as Diretrizes Curriculares Nacionais para os cursos de graduação em Psicologia, estabelecendo normas para o projeto pedagógico complementar para a formação de Professores em psicologia. Recuperado: 25 Jul. 2012. Disponível: http://www.portal.mec.gov.br/index.php?option=com_ content $\&$ view=article $\&$ id $=12991$
Veiga, I. P. A. (2010). Educação básica: projeto político pedagógico; Educação superior: projeto político pedagógico. Campinas, SP: Papirus.

Yamamoto, O. H., Da Rocha Falcão, J. T., \& Seixas, P. S. (2011). Quem é o estudante de Psicologia do Brasil? Avaliação Psicológica, 10(3), 209-232.

Recebido em: 10/01/2012

Reformulado em: 23/07/2012

Aprovado em: 05/11/2012

\section{Sobre os autores}

Pablo Sousa Seixas (pablo.seixas@gmail.com)

Psicólogo, doutorando do Programa de Pós-Graduação em Psicologia da Universidade Federal do Rio Grande do Norte e membro do Grupo de Pesquisas Marxismo e Educação. Campus Universitário Universidade Federal do Rio Grande do Norte, Centro de Ciências Humanas Letras e Artes, Departamento de Psicologia, sala 613, Lagoa Nova, Natal/RN, CEP 59078-970, Caixa-Postal: 1622.

Fellipe Coelho-Lima (fellipecoelholima@gmail.com)

Psicólogo, mestrando do Programa de Pós-Graduação em Psicologia da Universidade Federal do Rio Grande do Norte e membro do Grupo de Pesquisas Marxismo e Educação. Campus Universitário Universidade Federal do Rio Grande do Norte, Centro de Ciências Humanas Letras e Artes, Departamento de Psicologia, sala 613, Lagoa Nova, Natal/RN, CEP 59078-970, Caixa-Postal: 1622.

Suzany Gadelha Silva (suzany_ludimila@hotmail.com)

Psicóloga, mestranda do Programa de Pós-Graduação em Psicologia da Universidade Federal do Rio Grande do Norte e membro do Grupo de Pesquisas Marxismo e Educação. Campus Universitário Universidade Federal do Rio Grande do Norte, Centro de Ciências Humanas Letras e Artes, Departamento de Psicologia, sala 613, Lagoa Nova, Natal/RN, CEP 59078-970, Caixa-Postal: 1622.

Oswaldo Hajime Yamamoto (oswaldo.yamamoto@gmail.com)

Professor Titular do Departamento de Psicologia da Universidade Federal do Rio Grande do Norte e coordenador do Grupo de Pesquisas Marxismo e Educação. Campus Universitário Universidade Federal do Rio Grande do Norte, Centro de Ciências Humanas Letras e Artes, Departamento de Psicologia, sala 614, Lagoa Nova, Natal/RN, CEP 59078-970, Caixa-Postal: 1622.

Agradecemos o apoio financeiro concedido pelo Conselho Nacional de Desenvolvimento Científico e Tecnológico (CNPq) e pela Coordenação de Aperfeiçoamento de Pessoal de Nível Superior (CAPES). 